\title{
Kinetics and Mechanism of Decarburization and Melting of Direct-Reduced Iron Pellets in Slag
}

\author{
Jianghua Li and Mansoor Barati
}

\author{
Version Post-print/Accepted Manuscript \\ Citation Li, J. \& Barati, M. Metall and Materi Trans B (2009) 40: 17. \\ (published version) https://doi.org/10.1007/s11663-008-9195-x
}

Publisher's statement This is a post-peer-review, pre-copyedit version of an article published in Metallurgical and Materials Transactions B. The final authenticated version is available online at: http://dx.doi.org/10.1007/s11663-0089195-x

\section{How to cite TSpace items}

Always cite the published version, so the author(s) will receive recognition through services that track citation counts, e.g. Scopus. If you need to cite the page number of the author manuscript from TSpace because you cannot access the published version, then cite the TSpace version in addition to the published version using the permanent URI (handle) found on the record page.

This article was made openly accessible by $U$ of $T$ Faculty. Please tell us how this access benefits you. Your story matters. 


\title{
Kinetics and Mechanism of Decarburization and Melting of DRI Pellets in Slag
}

\author{
JIANGHUA LI and MANSOOR BARATI \\ An experimental study was conducted to understand the decarburization and melting behavior of DRI \\ pellets in $\mathrm{SiO}_{2}-\mathrm{Al}_{2} \mathrm{O}_{3}-\mathrm{CaO}-\mathrm{MgO}-\mathrm{FeO}$ slags with various $\mathrm{FeO}$ contents (10 to 25 wt pct) and basicities, \\ ranging from 1.5 to 2.5 . The behavior of the pellet in slag was observed using X-ray fluoroscopy technique \\ and the rate of decarburization was simultaneously measured with a constant volume pressure increase \\ technique. The study shows that the decarburization of DRI in slag at $1600{ }^{\circ} \mathrm{C}$ takes place in two stages; the \\ first stage is the reaction between $\mathrm{FeO}$ and carbon inside the pellet, which is controlled by heat transfer \\ from slag to the pellet. The second stage involves the decarburization reaction between the FeO in the slag \\ and the remaining carbon in the DRI. The kinetics of this stage is determined by mass transfer of FeO in \\ the slag and is strongly dependent on the FeO concentration. Depending on the physicochemical properties \\ of the slag and the rate of gas evolution, the DRI may sink through, float inside the slag, or remain on top \\ before complete decarburization.
}

\section{INTRODUCTION}

Direct Reduced Iron (DRI) is a major iron feedstock for many of today's steelmaking operations. Driven by the rising scrap price and the market's demand for high-quality clean steel, there has been a trend towards increasing the DRI charge into Electric Arc Furnaces (EAF) as a substitute for steel scrap. As a result, the DRI production has experienced a substantial increase in the last few decades from 0.8 million tons/year in 1970 to over 67 million tons/year in $2006^{[1]}$ and is expected to grow even more rapidly in the next decade. More than $95 \%$ of the DRI produced is used in the EAF and the proportion of DRI in the metallic feed typically exceeds $50 \%$. In some cases, $100 \%$ DRI has been used in the EAF.

Numerous advancements have emerged in the DRI-based steelmaking technology in recent years. Charging hot DRI to EAF to save the sensible heat of the DRI and reduce the energy consumption is among these. ${ }^{[2-7]}$ It has been reported that DRI can be conveyed to the $\mathrm{EAF}$ at $700^{\circ} \mathrm{C}$ and, as a consequence, the electrical energy consumption is reduced about $120 \mathrm{kWh}$ per ton of steel, which is approximately 20 to 30 percent savings in energy compared to existing cold-fed furnaces. Nevertheless, the advantages of the hot charging technology cannot be completely realized as a result of different operating modes of the EAF and DRI producing processes such as Midrex and HYL, where the former is a batch process and the latter are operated continuously. 
A novel steelmaking technology, Continuous Reduced Iron Steelmaking Process (CRISP), has been introduced ${ }^{[8-9]}$ to overcome the plant availability mismatch between the two processes by melting DRI and producing semi-finished steel in a continuous fashion. The technical aspects of the CRISP have been presented in detail elsewhere. ${ }^{[10-12]}$ Briefly, the process employs a large stationary electric arc furnace to continuously melt DRI and scrap and decarburize the steel with minimum or no addition of gaseous oxygen. Steel and slag are tapped periodically where the appropriate slag chemistry and long residence time will be used to lower the steel carbon to the desired levels. Critical aspects of the process are the mechanisms and the rates of decarburization and melting of DRI pellets as they are fed from the direct reduction module and pass through the slag phase. For instance, the feeding rate of DRI and the slag composition must be carefully controlled to ensure prompt melting of DRI pellets, decarburization of steel to the desired level, and good foaming to protect the sidewall refractory from electric arc radiation.

Despite the significant improvements and viability of the processes pertaining to DRI melting both in the conventional steelmaking and the CRISP, a limited number of studies have been reported in this area. ${ }^{[13-15]}$ Sadrnezhaad and Elliott ${ }^{[13-14]}$ measured the rates of gas formation and the temperature rise at the pellet core upon immersing DRI pellets in the induction melted metallurgical slags of various compositions. It was found that the gas evolution from DRI pellet took place mostly between $400{ }^{\circ} \mathrm{C}$ and $1200^{\circ} \mathrm{C}$ before the initial melting of DRI pellets. Two peaks of gas formation occurred at about $700{ }^{\circ} \mathrm{C}$ and $950{ }^{\circ} \mathrm{C}$. The peaks were related to $\mathrm{CO} / \mathrm{CO}_{2}$ gas generated during the reduction of $\mathrm{Fe}_{2} \mathrm{O}_{3} / \mathrm{Fe}_{3} \mathrm{O}_{4}$ to $\mathrm{FeO}$ (at $700{ }^{\circ} \mathrm{C}$ ) and FeO to metallic Fe (at $950^{\circ} \mathrm{C}$ ) according to Reaction [1].

$$
\mathrm{FeO}_{(D R I)}+\mathrm{C}_{(D R I)} \rightarrow \mathrm{Fe}_{(D R I)}+\mathrm{CO}_{(g)}
$$

The total volume of the gas released was limited by the availability of the carbon or FeO content of the DRI pellet depending on which one was completely consumed first.

Goldstein et al. ${ }^{[15]}$ investigated the behavior of cold DRI pellets dropped into hot metal-slag systems at $1460{ }^{\circ} \mathrm{C}$. The slag composition used in their experiments was $49 \mathrm{CaO}-41 \mathrm{SiO}_{2}-10 \mathrm{Al}_{2} \mathrm{O}_{3}$ (wt pct) The process was visualized using an $\mathrm{X}$-ray fluoroscopy technique and the rate of gas produced from the FeO reduction occurring in the DRI (Reaction [1]) was measured by a constant volume pressure increase method. Their observations indicated a short incubation period of about 2 to 4 seconds, followed by rapid gas evolution from the pellet that lasted between 20 to 30 seconds. During this time, a gas halo formed around the pellet causing the pellet to remain buoyant in the slag. Formation of the gas layer around the pellet was similar to the observations made by Min and Freuhan ${ }^{[16]}$ when a liquid Fe-C droplet was released into the slag. 
In the work by Goldstein et al., most of the CO gas from the DRI was evolved in the slag phase. A heat transfer model was developed to determine the heating rate of the DRI pellets in the slag. According to the model prediction, the gas evolution takes place within a temperature range of $800{ }^{\circ} \mathrm{C}$ and $1200{ }^{\circ} \mathrm{C}$ and is controlled by the heat transfer rate. This result is consistent with that of Sadrnezhaad and Elliott because DRI pellets used in this experiment only contained $\mathrm{FeO}_{(\text {no }} \mathrm{Fe}{ }_{2} \mathrm{O}_{3}$ and $\mathrm{Fe}_{3} \mathrm{O}_{4}$ ) so only the reduction of $\mathrm{FeO}$ to $\mathrm{Fe}$ occurred. The peak of the $\mathrm{CO}$ gas formation was at about $1000{ }^{\circ} \mathrm{C}$, which is close to $950{ }^{\circ} \mathrm{C}$ that was observed by Sadrnezhaad and Elliott.

These previous studies were mostly focused on the decarburization within the DRI pellet before its melting, but subsequent melting of DRI pellets and further decarburization by the FeO in the slag were not reported. However, this latter phenomenon plays a critical role in the overall decarburization kinetics, the final carbon content of the product, and the optimum feed rate of DRI, which is proportional to its melting rate. The present study aims to investigate the mechanisms and different steps involved in the overall melting and decarburization of DRI pellets in slags. Visual observations as well as measurements of the reaction rates will be made to provide a fundamental understanding of the mechanism of the processes and the possible rate controlling steps.

\section{EXPERIMENTAL WORK}

\section{A. Slag Composition}

Experiments were designed to investigate the decarburization rate and melting behaviour of DRI pellets in $\mathrm{SiO}_{2}-\mathrm{Al}_{2} \mathrm{O}_{3}-\mathrm{CaO}-\mathrm{MgO}-\mathrm{FeO}$ slags with various $\mathrm{FeO}$ contents and basicities. The basicity index used in this study is the modified V-ratio and defined as $\mathrm{B}=(\mathrm{MgO}+\mathrm{CaO}) /\left(\mathrm{SiO}_{2}+\mathrm{Al}_{2} \mathrm{O}_{3}\right)$. Five slag compositions shown in Table $\mathrm{I}$ were tested, covering a range of $\mathrm{FeO}$ from 10 to $25 \mathrm{wt}$ pct and basicity between 1.5 and 2.5. The $\mathrm{MgO}$ content was chosen to be 1 to 1.5 wt pct higher than the concentrations at the dual saturation point of $\mathrm{Ca}_{2} \mathrm{SiO}_{4}$ and magnesia-wustite $\mathrm{Mg}(\mathrm{Fe}) \mathrm{O}$ to simulate the operational conditions in EAF steelmaking for increased slag foaming and reduced refractory wear. ${ }^{[12]}$ The alumina content of the slag was maintained at $4 \mathrm{wt}$ pct, which is close to the concentration after complete dissolution of the DRI.

$<<$ Table I $>>$

\section{B. Materials}

Commercial DRI pellets obtained from Arcelor-Mittal were used for the study. The average chemical composition of DRI pellets is given in Table II. But the actual chemical composition of each individual DRI pellet deviates from the average. 
Table III lists the calculated carbon and $\mathrm{FeO}$ concentrations of the each pellet used in the experiments. The calculation method will be explained in Section III-B. As seen, the carbon content varied from $1.0 \%$ to $2.6 \%$ and FeO content changed from $4.5 \%$ to $11.5 \%$. Materials used for preparing the master slag included mill scale $(94.5 \% \mathrm{FeO})$, and reagent grade (>99.9) oxides $\mathrm{CaO}, \mathrm{MgO}, \mathrm{SiO}_{2}$ and $\mathrm{Al}_{2} \mathrm{O}_{3}$.

$<<$ Table II >>

$<<$ Table III >>

\section{Apparatus and Experimental Procedure}

A schematic of the experimental apparatus is shown in Fig. 1. A vertical tube resistance furnace with silicon carbide heating elements was used to heat the slag sample to the target temperature of $1600{ }^{\circ} \mathrm{C}$. One hundred grams of the slag forming materials were premixed in a small ball mill and then pressed into a disk. The preprocessed master slag disc was then loaded into a high density, high purity (>99.4\%) magnesia crucible $51 \mathrm{~mm}$ in diameter and $152 \mathrm{~mm}$ in height. The crucible was then placed inside the furnace heated very slowly $\left(1.7^{\circ} \mathrm{C} / \mathrm{min}\right)$ to $1600{ }^{\circ} \mathrm{C}$ under an $\mathrm{Ar}$ atmosphere. The temperature was automatically controlled by a EUROTHERM furnace power control system. During the experiments, the slag was located in the $50 \mathrm{~mm}$ hot zone of the furnace with temperature variations of $\pm 2{ }^{\circ} \mathrm{C}$. A B-Type (Pt-13\% Rh) thermocouple was installed just beneath the crucible to measure the temperature. The alumina reaction tube was sealed using water-cooled stainless steel caps and viton gaskets at the top and bottom ends with continuously purging of high-purity argon (99.99\% with less than 5 ppm oxygen and 5 ppm moisture) to avoid oxidation of the $\mathrm{FeO}$ in the slag.

\section{$<<$ Figure 1 >}

A one-hour hold time at the target temperature was used to homogenize the slag. A cold DRI pellet weighing approximately 2.2 grams and $10.5 \pm 0.5 \mathrm{~mm}$ in diameter was then dropped into the slag by removing a magnet that held the DRI at the top of the furnace. Due to the large distance (about $600 \mathrm{~mm}$ ) between the slag surface and DRI pellet holding position, the pellet temperature while suspending on top of the furnace remained low. The estimated temperature of DRI pellet before dropping into the slag was under $80^{\circ} \mathrm{C}$ based on the temperature measurement on the top cap in a test when there was no pellet inside the furnace, so that the cap was receiving direct radiation from the slag, as the pellet would. 
The behavior of the pellet in the liquid slag was observed and recorded by OEC 9800 Plus X-ray fluoroscopy system (GE OEC Medical systems). Still images and videos were recorded during the experiments. At the same time, a high accuracy pressure transducer capable of measuring pressure changes in the range zero to $69 \mathrm{kPa}$ was employed to measure the pressure increase (at constant volume) caused by the gas evolution. The volume of the gas generated by the reactions was then determined by calibrating the device. Known amounts of inert gas were injected to the furnace under the experimental conditions before the pellet was released and the corresponding pressure rise was recorded. The obtained correlation between the gas volume and the pressure was later used to calculate the volume of the evolved gas during the reaction. The image and pressure recordings were continued until the gas pressure became steady.

\section{RESULTS AND DISCUSSION}

\section{A. Visual observations of DRI behavior in slags}

Visual observations indicated an incubation period of 5 to 8 seconds after the pellet was dropped into the slag, followed by rapid gas evolution around the pellet. The incubation times in this study are longer than the incubation period of 2 to 4 seconds reported by Goldstein et al. ${ }^{[15]}$, which could be caused by the difference in the conditions that control the heat transfer rate to the pellet. These include the slag properties, density, porosity and metallization of DRI, and how the pellet enters the bath with respect to the intensity of impact and immersion. Also, the slight difference could be caused by the rather subjective determination of the exact incubation time.

The direct observations revealed that the behavior of DRI pellet in slags can be classified into three scenarios.

Scenario 1: the DRI pellet sinks into the bottom of the crucible from the beginning and a very thin and uneven gas halo forms around the pellet and causes the pellet to move along the bottom of the crucible from time to time. Fig. 2 represents this scenario which occurred for the slag with $\mathrm{FeO}$ of 18 wt pct and basicity of 2.0.

$<<$ Figure 2>>

Scenario 2: the pellet remains buoyant and moves around in the slag for most of the decarburization period and a relatively thick gas halo forms around the pellet. The pellet sinks to the bottom of the crucible only after it became a liquid droplet. Fig. 3 shows this scenario which occurred in the cases of $\mathrm{FeO}=25$ wt pct, $\mathrm{B}=2.0$ and $\mathrm{FeO}=18$ wt pct, $\mathrm{B}=1.5$. 
$<<$ Figure 3>>

Scenario 3: the pellet is partially immersed in the slag phase due to the high slag viscosity and the motion of the pellet is quite limited. This scenario was seen in the cases of $\mathrm{FeO}=10$ wt pct, $\mathrm{B}=2$ and $\mathrm{FeO}=18$ wt pct, $\mathrm{B}=2.5$. Fig. 4 represents one of these two cases.

$<<$ Figure 4>>

The behavior of the DRI pellet after it falls into the slag depends on the gas evolution rate from the pellet and slag properties such as density and viscosity, which will be discussed in detail later.

In all cases, it was observed that the pellet began to shrink after 16 to 26 seconds of immersion and a dense shell was formed around the pellet. The shrinkage was associated with the sintering of the outer layer of the porous DRI pellet which has experienced a first-stage reduction of $\mathrm{FeO}$. After the completion of the decarburization reactions, a flat-bottom, elliptical liquid metal droplet is typically formed which settles at the bottom of the crucible.

\section{B. Decarburization of DRI pellet in slags}

Fig. 5 represents the moles of gas evolved as a function of time for slags with various $\mathrm{FeO}$ concentrations and a constant basicity of 2.0. In the figure, the zero time is the beginning of the gas evolution and the incubation period of 5 to 8 seconds was not included in the graph.

$<<$ Figure 5>>

It is apparent from Fig. 5 that the decarburization process consists of two stages, labeled 1, 2 respectively. The first stage corresponds to the decarburization occurring inside the DRI pellet by the inherent $\mathrm{FeO}$ and carbon according to Reaction [1]. This stage 1 is completed in about 11 seconds for $\mathrm{FeO}$ at $25 \mathrm{wt}$ pct, $13 \mathrm{~s}$ for $\mathrm{FeO}$ at 18 wt pct and $18 \mathrm{~s}$ for $\mathrm{FeO}$ at 10 wt pct, indicating that the time needed for completing the reaction decreases with increasing $\mathrm{FeO}$ content in the slag.

$<<$ Table IV >> 
Previous works ${ }^{[13-15]}$ have shown that this stage of decarburization mostly takes place within a temperature range of $800{ }^{\circ} \mathrm{C}$ and $1200{ }^{\circ} \mathrm{C}$ for $\mathrm{FeO}$-containing DRI pellet (no $\mathrm{Fe}_{2} \mathrm{O}_{3}$ and $\mathrm{Fe}_{3} \mathrm{O}_{4}$ ) and is controlled by heat transfer from slag to the pellet. In this study, the heat transfer in the system is also likely to be the rate-controlling mechanism. In the study by Goldstein $e t$ al. ${ }^{[15]}$, the pellet was dropped into a slag at $1460^{\circ} \mathrm{C}$ with the first stage completed in 20 to 30 seconds. In this study, the time was between 10 to 20 seconds, where the shorter reaction time can be attributed to the higher temperature of the slag (1600 ${ }^{\circ} \mathrm{C}$ ). The higher temperature increases the rate of heat transfer, by both decreasing the slag viscosity (thus increasing convective heat transfer coefficient) and increasing the temperature gradient across the pellet-slag interface. The effect of $\mathrm{FeO}$ during the first stage on the reaction kinetics can be explained through its impact on heat transfer. Increasing $\mathrm{FeO}$ reduces the slag viscosity (see calculated viscosities in Table V), which in turn enhances the rate of heat transfer. This is predominantly because the pellet is submerged more rapidly and has better contact with the slag when the slag is less viscous.

According to Reaction [1], the total volume of the gas released during this first stage of decarburization is only decided by the availability of the carbon and $\mathrm{FeO}$ in the DRI pellet, depending on which one is completely consumed first. The difference in the total volume of the gas evolved for the three curves suggests that the initial carbon (or FeO) content in each individual DRI pellet was different despite the fact that they were from the same batch. Although nondestructive analysis of individual pellets used in each experiment for determination of $\mathrm{C}$ and $\mathrm{FeO}$ were not possible, they could be calculated after each experiment (Table III). The total carbon in the pellet equates the sum of the carbon reacting with $\mathrm{FeO}$ and the remaining carbon in the metal droplet. The former can be derived from the total $\mathrm{CO}$ volume generated during the whole decarburization process and the latter can be measured after the experiments. Since decarburization reaction continued after the first stage decarburization for all the pellets, it can be concluded that it was the $\mathrm{FeO}$ that was consumed first and fixed the total volume of generated gas during the first stage decarburization.

During the second stage that is identified by a sudden slope change in the gas evolution rate, the remaining carbon in the DRI pellet reacts with $\mathrm{FeO}$ in the slag. In all cases, the rate of secondary gas evolution is clearly slower than the first stage. Densification of the outer side of the pellet and shell formation occurred in this stage of decarburization.

\section{Effects of the slag $\mathrm{FeO}$ content on decarburization rate}


Figure 6 presents the decarburization rate as a function of the initial FeO content in the slag for the secondary decarburization. It is apparent that the rate increases significantly with the increasing FeO content of the slag.

$<<$ Figure 6>>

It is generally agreed that the reaction between $\mathrm{FeO}$ in the slag with the carbon in the melt or solid carbon occurs through an intermediate gas halo containing $\mathrm{CO}$ and $\mathrm{CO}_{2}{ }^{[16-21]}$. The formation of a gas film around the pellet was also evident in the current study as discussed earlier. The reaction between slag and the remaining carbon thus takes place through this intermediate gas layer, i.e., $\mathrm{CO}$ reduces $\mathrm{FeO}$ at the slag-gas interface (Reaction [2]) to produce $\mathrm{CO}_{2}$, which is later consumed by Reaction [3] at the gas-metal interface to regenerate $\mathrm{CO}$.

$$
\begin{aligned}
& \mathrm{CO}_{(\mathrm{g})}+\mathrm{FeO}=\mathrm{Fe}+\mathrm{CO}_{2} \\
& \mathrm{CO}_{2}+\mathrm{C}=2 \mathrm{CO}
\end{aligned}
$$

The following possible rate-limiting steps were proposed by Min and Fruehan ${ }^{[16]}$ :

1. Mass transfer of FeO from the bulk of the slag to the slag-gas interface with the rate expressed as:

$$
J_{\mathrm{FeO}}=k_{m}\left[(\mathrm{FeO})_{b}-(\mathrm{FeO})_{i}\right]
$$

Where $J_{\mathrm{FeO}}$ is the flux of $\mathrm{FeO}$ and $k_{m}$ is the liquid phase mass transfer coefficient of $\mathrm{FeO}$ in the slag. $(\mathrm{FeO})_{b}$ is the $\mathrm{FeO}$ content in the slag bulk and $(\mathrm{FeO})_{i}$ is the $\mathrm{FeO}$ content at the slag-metal interface. Provided that this step plays the rate limiting step role, the interfacial reaction itself is at equilibrium and $(\mathrm{FeO})_{i}$ becomes the equilibrium $\mathrm{FeO}$ content for Reaction [1] with $\mathrm{P}_{\mathrm{CO}}=1$ atm and is essentially zero. Therefore, the decarburization rate should increase linearly with increasing FeO content in the slag bulk for this proposed rate-limiting step.

2. Interfacial gas-slag reaction (Reaction [2])

3. Gas diffusion $\left(\mathrm{CO}\right.$ or $\left.\mathrm{CO}_{2}\right)$ in the gas halo

4. Boudouard reaction (Reaction [3])

5. Diffusion of carbon in the melt 
Min and Fruehan suggested a mixed control model consisting of $\mathrm{CO}_{2}$ transport in the gas phase and $\mathrm{FeO}$ transport in the slag phase in the case that the sulfur content in the melt is lower than $0.01 \mathrm{wt}$ pct, which applies to the conditions of the present study. The estimated rate constants by Min and Fruehan are $4 \times 10^{-7}-4 \times 10^{-6} \mathrm{~mol} \cdot \mathrm{cm}^{-2} \cdot \mathrm{s}^{-1}(\mathrm{pct} \mathrm{FeO})^{-1}$ for mass transfer of $\mathrm{FeO}$ in the slag and $5 \times 10^{-7}-5 \times 10^{-6} \mathrm{~mol} \cdot \mathrm{cm}^{-2} \cdot \mathrm{s}^{-1}(\mathrm{pct} \mathrm{FeO})^{-1}$ for the gas diffusion in the gas halo. The measured apparent rate constant values in this work are listed in Table V. The area of the reaction surface is based on the mean value of the initial pellet area and the final liquid droplet area assuming the volume of the final droplet shrinks to $1 / 3$ of the pellet's initial volume. The volume change was estimated by measuring the volume of the final metal droplet in the slag after the experiments.

$<<$ Table V >>

As seen in Table $\mathrm{V}$ the decarburization rate constants determined from this work are within the range reported by Min and Fruehan for gas and liquid phase mass transfer rates. The exception is the rate constant for the slag containing $10 \mathrm{wt}$ pct $\mathrm{FeO}$, that is smaller than those rates. In this experiment, the higher viscosity of the slag caused the pellet to be only partly immersed in the slag prior to melting. The actual contact area was smaller than the estimated area used in the calculations, which causes the calculated rate to be underestimated. Therefore, it can be concluded that although the first stage is heat transfer controlled, the second stage of the reaction under the performed experimental conditions is controlled either by liquid phase mass transfer, gas phase diffusion, or a mixed mechanism involving both. The estimated rate of gaseous diffusion by Min and Fruehan presents the minimum rate for this mechanism since they assumed that the gas in the halo is stagnant except for the transportation of $\mathrm{CO}_{2}$. However, the disturbance in the gas film caused by moving of the DRI pellet inside slag, which was observed in this study would increase the rate constant to higher values. Therefore, it is expected that the rate of gas phase diffusion is higher than those reported and this mechanism can be eliminated as a likely rate limiting step. Consequently, $\mathrm{FeO}$ transport through the liquid slag phase is the most likely mechanism controlling the overall rate of reaction in the second stage of decarburization.

According to Equation [4], if the mass transfer coefficient $k_{m}$ is constant, the decarburization rate should increase linearly with increasing $\mathrm{FeO}$ content in the slag bulk. However, Fig. 6 shows a stronger correlation with a larger than first-order effect of the $\mathrm{FeO}$ on the rate. The mass transfer coefficient of $\mathrm{FeO}$ in the slag depends on both slag physicochemical properties and the gas evolution rate from the DRI pellet because both of them influence the relative movement of slag and 
pellet and the thickness of the diffusion film in the vicinity of DRI. As the FeO content increases from 10 to 25 wt pct, the slag viscosity deceases significantly as shown in Table $\mathrm{V}$, which results in an increase of the mass transfer. This is in accord with the measured apparent rate constant increasing from $1.1 \times 10^{-7}$ to $7.6 \times 10^{-7} \mathrm{~mol} \cdot \mathrm{cm}^{-2} \cdot \mathrm{s}^{-1} \cdot(\mathrm{pc} \mathrm{FeO})^{-1}$ in the same range of $\mathrm{FeO}$. Therefore, a larger than first-order effect of the $\mathrm{FeO}$ on the rate as seen in Fig. 6 is consistent with the FeO mass transfer being rate limiting step.

\section{Effects of slag basicity on decarburization}

Figure 7 presents moles of gas evolved versus time for the slags containing 18 pct FeO and various basicities. Similar to Fig. 5 , the process consists of two stages, the first stage completed in 10 to 20 seconds.

$<<$ Figure 7>>

As seen in Table V, the rate constants of the second stage decarburization for $\mathrm{B}=1.5,2.0$ and 2.5 are $4.0 \times 10^{-7}, 4.1 \times 10^{-7}$ and $1.6 \times 10^{-6} \mathrm{~mol} \cdot \mathrm{cm}^{-2} \cdot \mathrm{s}^{-1} \cdot(\mathrm{pct} \mathrm{FeO})^{-1}$, respectively. Although these values are again within the rate constant range of $\mathrm{FeO}$ mass transfer in the slag, their variations are not consistent with the differences in slag viscosity. As discussed earlier, the $\mathrm{FeO}$ mass transfer rate is not only a function of viscosity, but also dependent on the relative movement of slag and pellet. The latter is affected in turn by both viscosity of slag and the rate of gas evolution. Therefore, if the rate of gas evolution is slow, for example due to lower carbon content of the DRI, the slag properties predominantly control the rate, whereas when gas evolution is high, slag properties assume a secondary role. The visual observation for slags with $\mathrm{B}=1.5$ shows that the DRI pellet floated in the slag during most of the process due to the strong gas evolution rate of $2.11 \times 10^{-4} \mathrm{~mol} / \mathrm{s}$ in the first stage of decarburization. This is believed to be the primary reason for the large mass transfer coefficient, despite the high viscosity of this slag. Clearly, the high rate of gas release and the resultant pellet motion gives rise to a thinner diffusion film, which in turn increases the mass transfer coefficient. In contrast, the DRI pellet was stagnant at the bottom of the crucible for most of the time in the case of $B=2.0$ slag, due to the weaker gas evolution of $8.35 \times 10^{-5} \mathrm{~mol} / \mathrm{s}$ in the first stage of decarburization. This explains the reason for the smaller rate constant associated with this slag.

As for the slag with $B=2.5$, the calculated viscosity for this slag (Table $\mathrm{V}$ ) indicates that the slag has to be less viscous compared to those with lower basicity, thus one would expect a larger rate constant. However the observations proved that the melt was more viscous than the other slags. The slag viscosity calculations were made by estimating the fraction of solid particles in the slag, employing FactSage ${ }^{\circledR}$ thermodynamic package ${ }^{[25]}$, and including its effect on viscosity using an equation 
by Roscoe. ${ }^{[23]}$ The higher than expected viscosity could be due to inaccuracy of the calculations for solid fraction and viscotiy models. For this slag, despite the strong gas evolution in the first-stage of decarburization, the mobility of DRI in the slag phase was very limited, which resulted in a relatively small rate constant value.

The above discussions suggest that the rate of the second stage decarburization is increased by DRI remaining buoyant in the slag. The conditions that give rise to this phenomenon are adequate slag fluidity, and strong gas evolution. Since the latter is controlled by the reaction between $\mathrm{FeO}$ of slag and carbon of DRI, the reaction has a self-accelerating characteristic, i.e. higher reaction rate promotes gas generation, that in turn accelerates the reaction itself.

\section{E. Slag foaming}

Significant slag foaming, characterized by the increase in the slag height, were observed in the cases of $\mathrm{FeO}=25 \mathrm{wt}$ pct, $\mathrm{B}=2$ and $\mathrm{FeO}=18$ wt pct, $\mathrm{B}=1.5$. The gas evolution was strong and the slag appeared to have proper properties to sustain the foam. In the case of $\mathrm{FeO}=18$ wt pct, $\mathrm{B}=2.0$, the foaming was observed at times, but inconsistent due to the weak gas evolution. For $\mathrm{FeO}=10$ wt pct, $\mathrm{B}=2.0$ and $\mathrm{FeO}=18$ wt pct, $\mathrm{B}=2.5$, foaming was not seen due to the high slag viscosity despite the relatively strong gas evolution. It may be concluded that the conditions that promote flotation of DRI in the slag are desirable for good slag foaming.

\section{CONCLUSIONS}

The simultaneous direct observations and gas flow measurements on DRI pellets dropped into slag revealed that:

1. After the cold pellet enters the slag, there is an incubation period of 5 to 8 seconds, followed by rapid gas evolution from the pellet. The pellet remains buoyant in slag and a gas halo forms around the pellet when conditions promote strong gas evolution and the slag viscosity is appropriate, i.e. not too high to prevent movement of the pellet. The DRI pellet sinks to the bottom of the crucible from the beginning if the gas evolution is weak. In the case of high slag viscosity, the pellets tend to stay partially immersed in the slag phase and the motion of the pellet is limited.

2. The decarburization of DRI pellet in FeO-containing slag is a two-stage process provided that the pellet has carbon in excess of that required for complete reduction of the pellet FeO. The first stage of decarburization takes place due to the reaction between $\mathrm{FeO}$ and carbon within DRI pellet. The second stage involves the reaction between $\mathrm{FeO}$ in the slag and the remaining carbon in the DRI pellet. 
3. After an initial incubation time of 5-8 seconds, the first stage of decarburization was completed in approximately 10 to 20 seconds after the start of gas evolution, depending on slag composition. The rate of gas evolution and the total gas released are determined by the heat transfer rate and the amount of $\mathrm{C}$ or $\mathrm{FeO}$ available for reaction respectively.

4. The secondary stage of decarburization was completed approximately 30 to 60 seconds after the first-stage of decarburization. The gas evolution rate is slower than that of the first-stage. A strong correlation between the secondary decarburization rate and the slag $\mathrm{FeO}$ exists, and findings in this work support the FeO mass transfer in the slag being the rate limiting step.

5. The decarburization rate of DRI in the second stage is significantly affected by its floatability in the slag. This is in turn controlled by the slag physical properties as well as the rate of gas evolution itself. The reaction thus has a self-accelerating characteristic.

\section{ACKNOWLEDGMENTS}

The authors acknowledge Hatch and Ontario Centers of Excellence for providing funding of this research. The assistance by Dr. F. Ji and Ms. E. Chen from McMaster University for setting up the experimental furnace and the X-ray machine is greatly appreciated.

\section{Refenrences}

1. World Direct Reduction Statistics -2007, Midrex, Charlotte, NC, USA, 2006, pp. 2-4.

2. S. Montague and W.D. Hausler, Direct from Midrex, 1999, $4^{\text {th }}$ Quarter, pp. 3-7.

3. R. Bailey, Direct from Midrex, 2001, $2^{\text {nd }}$ Quarter, pp. 7-8.

4. S. C. Montague, and W. D. Haysler, Proc. 57 th Electric Furnace Conference, Pittsburgh, USA, 1999, pp. 607-614.

5. G. Whitten, Direct from Midrex, 1998, $3^{\text {rd }}$ Quarter, pp. 3-5.

6. D. Quintero Yanez, Proc. $4^{\text {th }}$ European Electric Steel Congress, Madrid, 1992, pp. $273-283$.

7. P.E. Duarte and R. Lopez, Iron Steel Eng., 1996, vol. 73, no. 11, pp. 38-41.

8. F.M. Wheeler and Y.M. Gordon, Proc. $7^{\text {th }}$ European Electric Steelmaking Conference, Venice, Italy, 2002, pp. 2.437-2.446. 
9. F.M. Wheeler and Y.M. Gordon, Proc. of ISSTech Conf., Indianapolis, USA, 2003, pp. 1033-1041

10. Y. Gordon and F. Wheeler, US Patent No. 6,785,251, 2005

11. F. Wheeler, F. Atkinson, Y. Gordon, S. Broek, V. So, M. Barati, SCANMET III ( ${ }^{\text {rd }}$ International Conference on Process Development in Iron and Steelmaking, June 2008, Luleå, Sweden)

12. Li, M. Barati, Y. Yang., Proc. the 4th International Congress on the Science and Technology of Steelmaking (ICS 2008), October 6-8, 2008, Nagaragawa Convention Center, Gifu, Japan.

13. K. Sadrnezhaad and J. F. Elliott, Iron Steel Int., 1980, vol. 53, no. 6, pp. 327-339.

14. K. Sadrnezhaad, "Continuous Melting of Metallised Ore Pellets", Iron Steel Int., 1981, vol. 54, no. 6, pp. 309-314.

15. D.A. Goldstein, R.J. Fruehan and B. Ozturk, Iron and Steelmaker, 1999, vol. 26, no. 2, pp. $49-61$.

16. D. J. Min and R. J. Fruehan, Metall. Mater. Trans. B, 1992, vol. 23B, pp. 29-37.

17. B. Sarma, A.W. Cramb and R.J. Fruehan, Metall. Mater. Trans. B, 1996, vol. 27B, pp. 717-731.

18. N. Siddiqi, B. Bhoi, R.K. Paramguru, V. Sahajwalla and O.Ostrovski, Ironmaking and Steelmaking, 2000, vol. 27, no. 5, pp. 367-372.

19. R.D. Morales, R. Lule, F. Lopez, J. Camacho and J.A. Romero, ISIJ Int., 1995, vol. 35, pp. $1054-1062$.

20. R.J. Fruehan, "Future Steelmaking Technologies and the Role of Basic Research", Metall. Mater. Trans. B, 1997, vol. 28B, pp. 743-753.

21. D.J. Min, J.W. Han and W.S. Chung, Metall. Mater. Trans. B, 1999, vol. 30B, pp. 215-221.

22. G. Urbain, F. Cambier, M. Deletter, M.R. Anseau, Trans. J. Br. Ceram. Soc., 1981, vol. 80, pp. 13941.

23. R. Roscoe, Br. J. Appl. Phys. 1952, vol. 3, pp. 267-269.

24. K.C. Mills and B. J. Keene, Int. Mater. Rev., 1987, vol. 32, pp. $1-120$.

25. C.W. Bale, P. Chartrand, S.A. Degterov, G. Eriksson, K. Hack, R. Ben Mahfoud, J. Melançon, A.D. Pelton and S. Petersen, Calphad, 2002, vol. 26, pp. 189 - 228. 
Table I. Slag compositions used in the experiments

\begin{tabular}{ccccccc}
\hline Exp. \# & $\mathrm{FeO} \mathrm{wt} \%$ & $\mathrm{SiO}_{2} \mathrm{wt} \%$ & $\mathrm{Al}_{2} \mathrm{O}_{3} \mathrm{wt} \%$ & $\mathrm{CaO} \mathrm{wt} \%$ & $\mathrm{MgO}$ wt\% & Basicity \\
\hline 1 & 25.0 & 21.0 & 4.0 & 38.0 & 12.0 & 2.0 \\
2 & 10.0 & 26.0 & 4.0 & 48.0 & 12.0 & 2.0 \\
3 & 18.0 & 23.3 & 4.0 & 42.7 & 12.0 & 2.0 \\
4 & 18.0 & 28.8 & 4.0 & 35.2 & 14.0 & 1.5 \\
5 & 18.0 & 19.4 & 4.0 & 50.0 & 8.5 & 2.5 \\
\hline
\end{tabular}

Table II. Average chemical composition of the DRI pellets (wt pet)

\begin{tabular}{ccccccc}
\hline Total Fe & Metallization & $\mathrm{C}$ & $\mathrm{S}$ & $\mathrm{SiO}_{2}$ & $\mathrm{Al}_{2} \mathrm{O}_{3}$ & $\mathrm{CaO}+\mathrm{MgO}$ \\
\hline 92.0 & 95.0 & 2.2 & 0.006 & 2.15 & 0.50 & 1.1 \\
\hline
\end{tabular}

Table III. Calculated FeO and carbon contents in each DRI pellet (wt pct)

\begin{tabular}{cccccc}
\hline Exp. \# & 1 & 2 & 3 & 4 & 5 \\
\hline FeO wt\% & 4.5 & 9.9 & 3.6 & 8.0 & 11.5 \\
C wt\% & 1.8 & 1.9 & 1.0 & 2.5 & 2.6 \\
\hline
\end{tabular}

Table IV. Measured gas generation rate and completion time for two different stages of decarburization process for various test conditions

\begin{tabular}{lccccc}
\hline \multicolumn{1}{c}{ Experimental Conditions } & $\begin{array}{c}\mathrm{FeO}=10 \% \\
\mathrm{~B}=2.0\end{array}$ & $\begin{array}{c}\mathrm{FeO}=18 \% \\
\mathrm{~B}=2.0\end{array}$ & $\begin{array}{c}\mathrm{FeO}=25 \% \\
\mathrm{~B}=2.0\end{array}$ & $\begin{array}{c}\mathrm{FeO}=18 \% \\
\mathrm{~B}=1.5\end{array}$ & $\begin{array}{c}\mathrm{FeO}=18 \% \\
\mathrm{~B}=2.5\end{array}$ \\
\hline Time period for completion of Stage 1 (s) & 18 & 13 & 11 & 10 & 13 \\
Time period for completion of Stage 2(s) & 31 & 45 & 36 & 33 & 58 \\
Rate of moles of gas evolved for Stage 1(mol/s) & $1.74 \times 10^{-4}$ & $8.35 \times^{-5}$ & $1.26 \times 10^{-4}$ & $2.11 \times 10^{-4}$ & $3.48 \times 10^{-4}$ \\
Rate of moles of gas evolved for Stage 2(mol/s) & $2.81 \times 10^{-6}$ & $1.89 \times 10^{-5}$ & $4.86 \times 10^{-5}$ & $7.29 \times 10^{-5}$ & $1.85 \times 10^{-5}$ \\
\hline
\end{tabular}


Table V. Calculated slag properties and the measured decarburization rates for various test conditions

\begin{tabular}{|c|c|c|c|c|}
\hline Test Conditions & $\begin{array}{l}\text { Slag Viscosity } \\
\left(\text { Ns.m. }^{-2}\right)^{[22,23]}\end{array}$ & $\begin{array}{l}\text { Slag Density } \\
\text { Kg.m }^{-3}[24]\end{array}$ & $\begin{array}{l}\text { Surface Tension } \\
\quad\left(\mathbf{N} \cdot m^{-1}[24]\right)\end{array}$ & 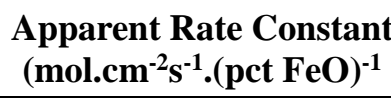 \\
\hline $\mathrm{FeO}=10 \%, \mathrm{~B}=2$ & 2.82 & 2640 & 0.59 & $1.1 \times 10^{-7}$ \\
\hline $\mathrm{FeO}=18 \%, \mathrm{~B}=2$ & 2.30 & 2784 & 0.59 & $4.1 \times 10^{-7}$ \\
\hline $\mathrm{FeO}=25 \%, \mathrm{~B}=2$ & 1.94 & 2910 & 0.60 & $7.6 \times 10^{-7}$ \\
\hline $\mathrm{FeO}=18 \%, \mathrm{~B}=1.5$ & 2.80 & 2784 & 0.57 & $1.6 \times 10^{-6}$ \\
\hline $\mathrm{FeO}=18 \%, \mathrm{~B}=2.5$ & 1.95 & 2784 & 0.61 & $4.0 \times 10^{-7}$ \\
\hline
\end{tabular}

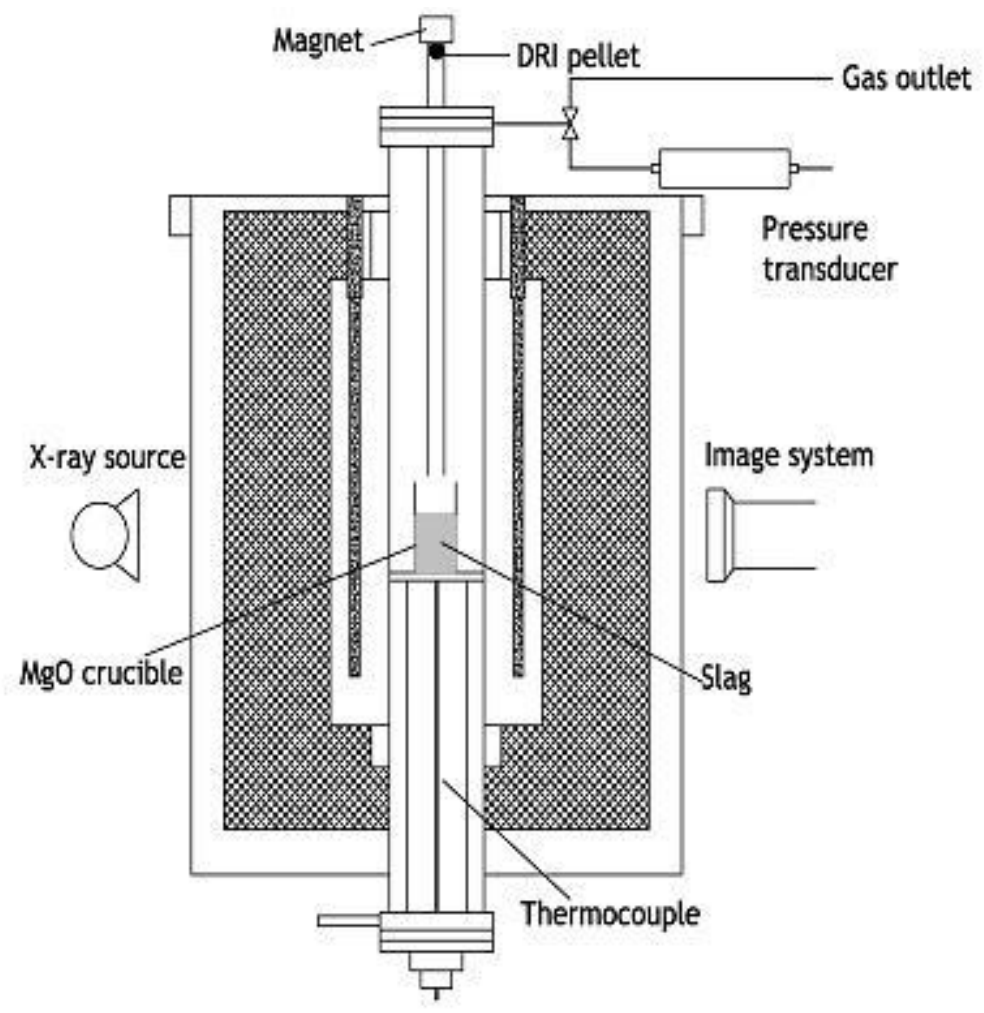

Fig. 1- Schematic diagram of experimental apparatus 

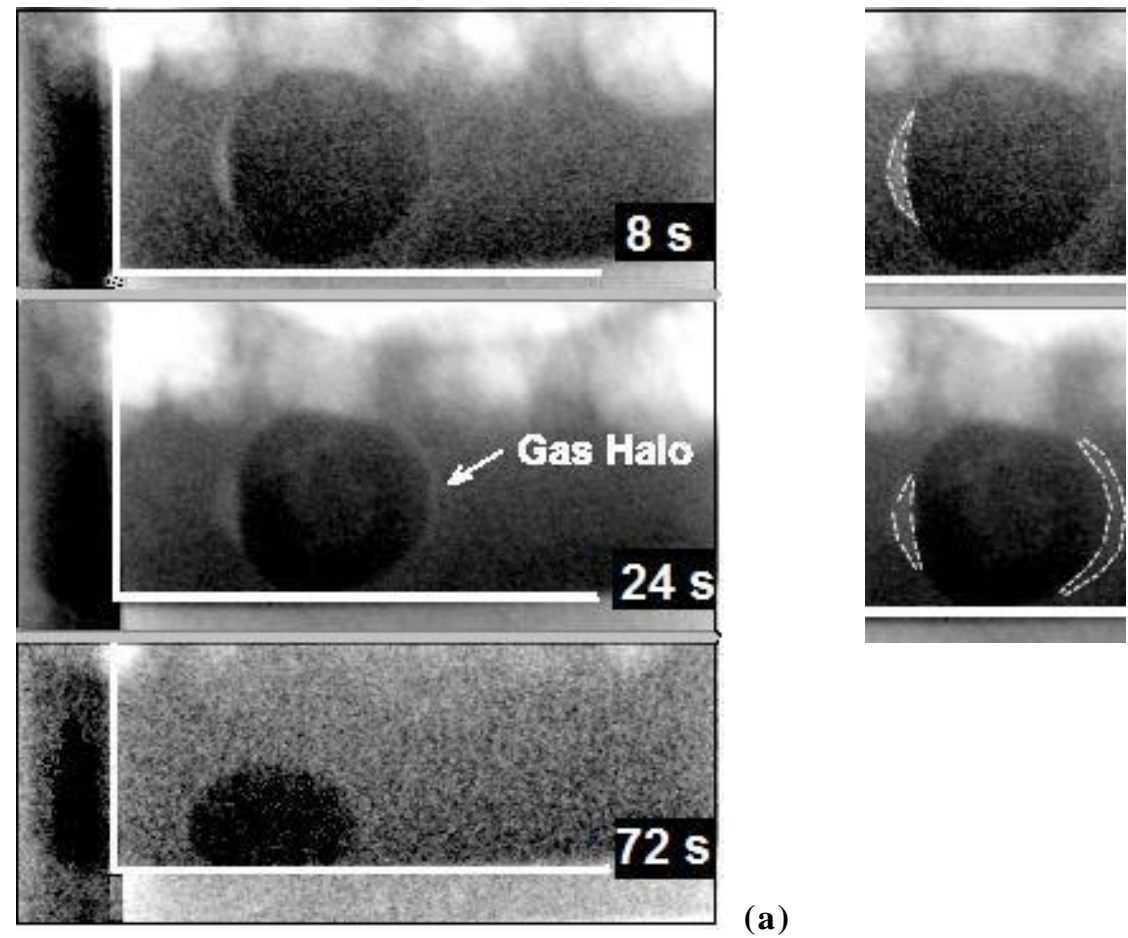

(b)

(a)

Fig. 2- DRI pellet settled to the bottom of the crucible from the beginning $(B=2, F e O=18$ wt pet). The vertical and horizontal white lines on (a) represent the wall and bottm of the crucible, respectively. The dashed lines on (b) indentify the gas halo.
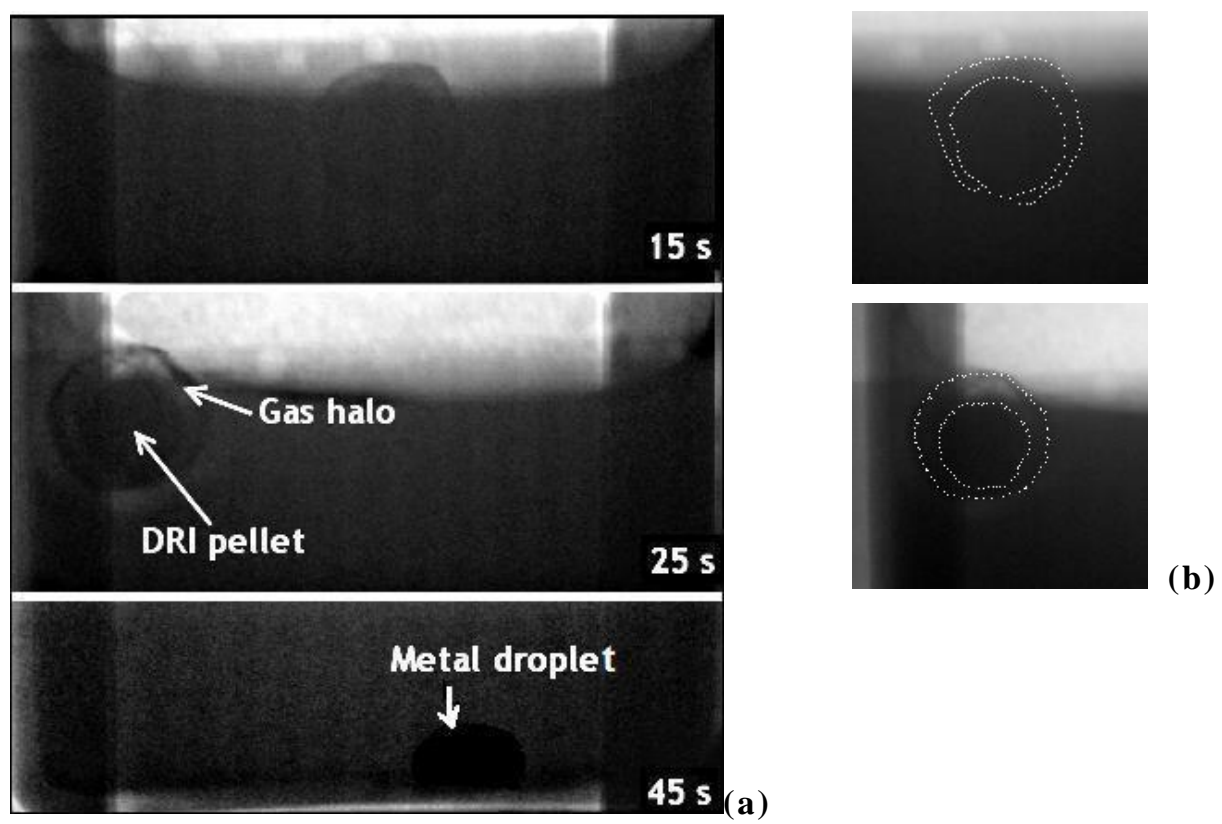

Fig. 3- DRI pellet floating in the slag with $B=2$ and 25 wt pet $\mathrm{FeO}$ (a) and (b) gas halo identified around the pellet 


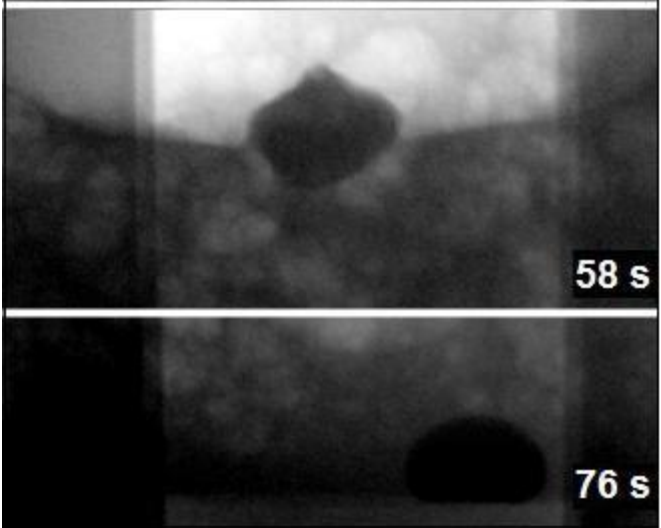

Fig. 4- DRI pellet is half-immersed in the slag and sinks only after melting $(B=2, \mathrm{FeO}=10 \mathrm{wt}$ pct $)$

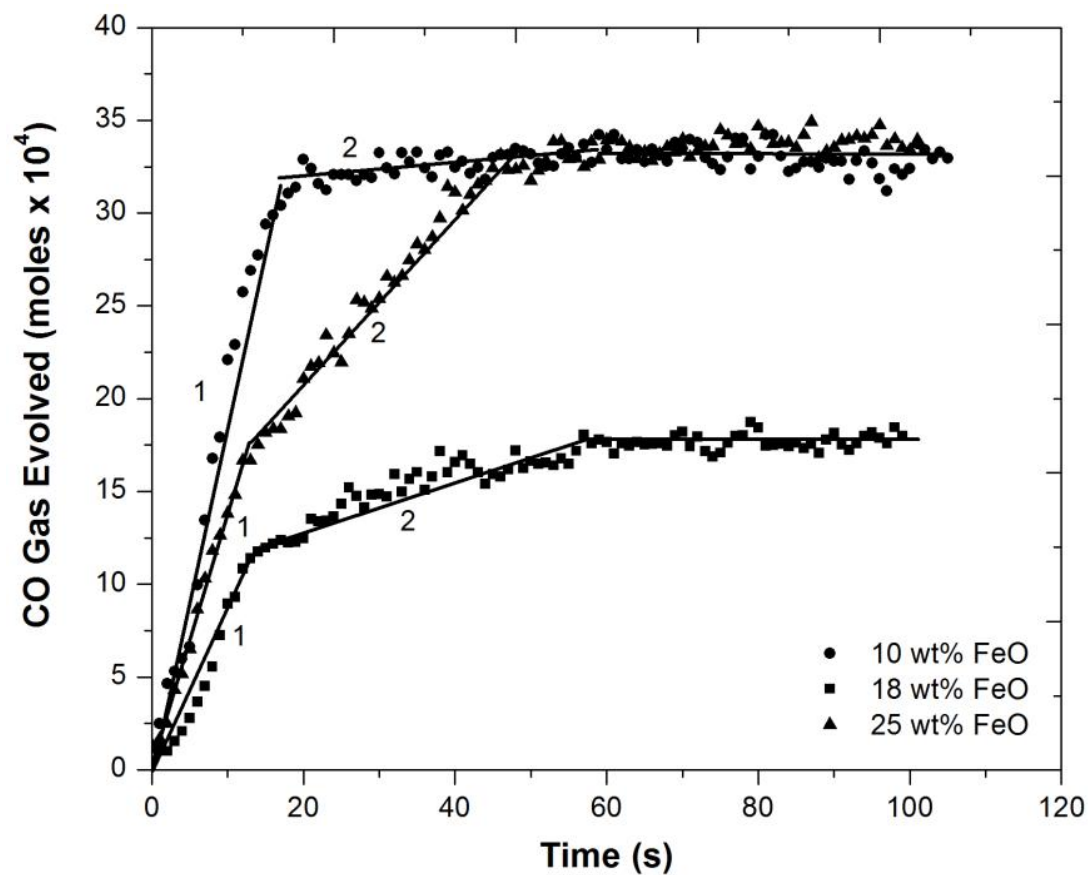

Fig. 5- Moles of gas evolved versus time for various $\mathrm{FeO}$ with $\mathrm{B}=2$ 


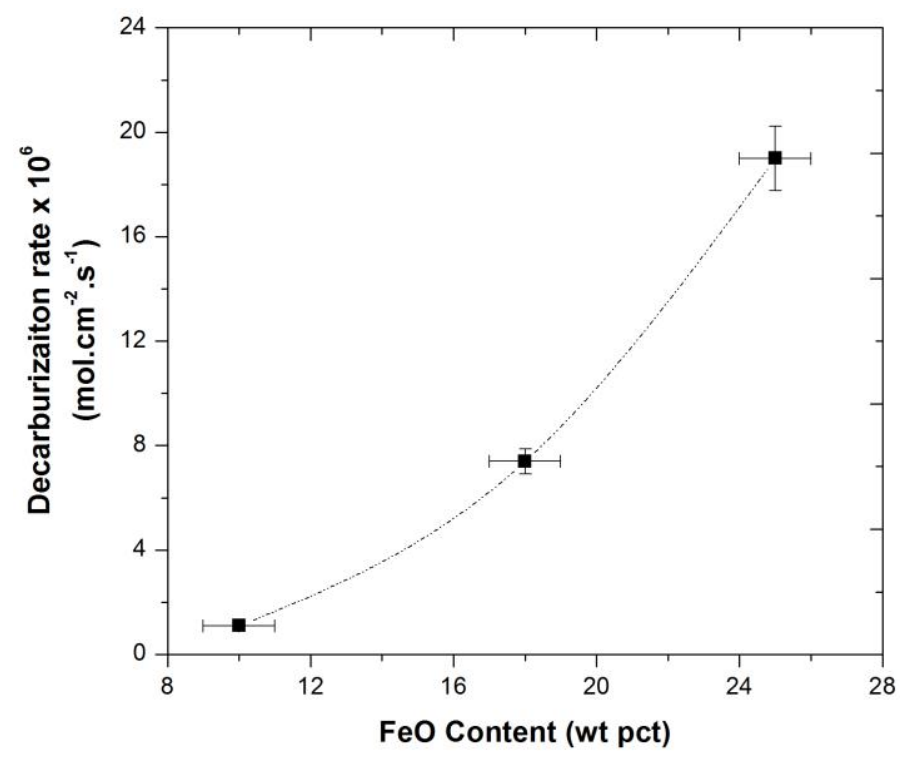

Fig. 6- Decarburization rate versus initial FeO content of slag for the second-stage decarburization. The dotted line is a guideline.

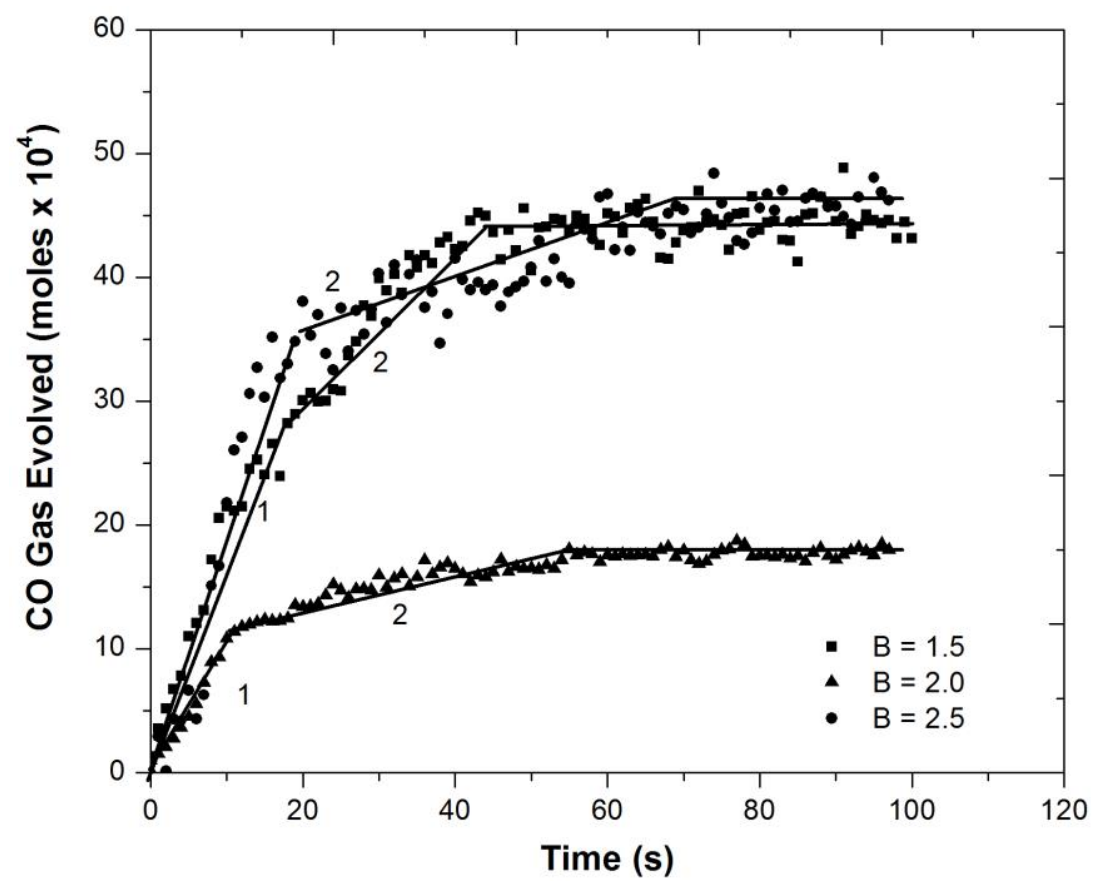

Fig. 7- Gas evolution versus time for various slag bacisities $(\mathrm{FeO}=18 \mathrm{wt}$ pct $)$ 